\title{
LA INMEDIATEZ COMUNICATIVA FRENTE A LA AUTONOMÍA LITERARIA: UN DEBATE DE LA LENGUA NACIONAL EN ARGENTINA
}

\author{
Ana Davis González \\ (Universidad de Sevilla) \\ adavis@us.es
}

\begin{abstract}
RESUMEN: En 1997, Wulf Oesterreicher reemplaza la tradicional antítesis oralidad/escritura por inmediatez comunicativa/distancia comunicativa respectivamente. El fin del presente trabajo es poner en relación tal dicotomía con la autonomía/dependencia de los textos literarios con respecto a su nacionalismo cultural; es decir, cómo afecta el grado de imitación o alejamiento del habla oral en la posición que ocupa el texto dentro de su campo literario. Para examinar nuestra hipótesis, nos serviremos de las polémicas acerca de la oralidad en la literatura argentina. Tras un breve resumen diacrónico, nos centramos en el período de los años cuarenta y en el modo en que los escritores vinculan la inmediatez comunicativa con la cultura nacional mientras que otros, como Borges, se oponen a esa asimilación.

PALABRAS CLAVE: inmediatez comunicativa, distancia comunicativa, autonomía literaria, literatura argentina, lengua nacional.
\end{abstract}

\section{COMMUNICATIVE INMEDIACY VERSUS LITERARY AUTONOMY: A DEBATE ABOUT NATIONAL LANGUAGE IN ARGENTINA}

ABSTRACT: In 1997, Wulf Oesterreicher replaced the traditional orality/writing antithesis with communicative immediacy/communicative distance respectively. Based on his suggestion, our aim is to link such dichotomy with the autonomy/dependence of literary texts with respect to their cultural nationalism; that is, how the degree of imitation or distancing from oral speech affects the position that the text occupies within its literary field. To examine our hypothesis, we will use the policies about orality in Argentine literature. After a brief diachronic summary, we focus on the period of the 1940s and on how writers link communicative inmediacy with national culture, while others, like Borges, oppose this assimilation.

KEYWORDS: communicative immediacy, communicative distance, literary autonomy, argentine literature, national language.

\section{INTRODUCCIÓN}

En La República mundial de las Letras (2001), Pascale Casanova describe el funcionamiento del campo literario mundial a partir de la emergencia de los nacionalismos europeos en el siglo XVIII. La autora indica que el nacionalismo significa un cambio de paradigma en los valores literarios por la asimilación indisoluble entre nación y lengua. Por ello, entre todas las manifestaciones artísticas, la literatura sería la más condicionada por el nacionalismo debido a que su cauce de acción es el lenguaje. Así, a partir de los siglos XVIII y XIX, los escritores no pueden desligarse de la nación, ya sea para enjuiciarla o para reivindicarla porque lo que se escribe y cómo se escribe tendrá siempre una connotación a favor o en contra del nacionalismo. De esta manera, en 
ese espacio virtual que constituye la república mundial de las letras irán adquiriendo prestigio aquellos escritores que logren alcanzar cierta autonomía respecto a los intereses nacionales mediante obras susceptibles de ser universalizadas o exportadas fuera de su país. Siguiendo la teoría de campos de Pierre Bourdieu (1995) y la hipótesis de los polisistemas de Even-Zohar (1968), Casanova establece la autonomía como criterio principal que ordena la bolsa de los valores literarios de ese espacio literario virtual. «Autonomía» significa independencia de lo que se escribe y cómo se escribe en relación con la política nacional: «es la oposición declaradaal principio del nacionalismoliterario, o sea, la lucha contra la intrusión política en el universo literario» (Casanova, 2001: 121). En palabras de Bourdieu: «A medida que el campo va ganando autonomía, el escritor se siente cada vez más autorizado a escribir obras destinadas a ser descifradas, por lo tanto sometidas a la lectura repetida que es necesaria para explorar, sin agotarla, la polisemia intrínseca de la obra» (1999: 448).

En el siglo XIX, París emerge como capital de esa gran república porque se halla a la vanguardia de la búsqueda por la autonomía en todos los órdenes artísticos —incluso la moda indumentaria - Francia, en términos de Even-Zohar, se encuentra en el centro del polisistema literario decimonónico frente al resto de los países periféricos aunque, como es sabido, entre centro y periferia no hay una diferencia binaria sino de continuum. Así, en el siglo XIX, países como Inglaterra o Alemania se acercan más al centro que las naciones hispanoamericanas que se encuentran aún en proceso de emancipación respecto de Europa. Como es sabido, en el Nuevo Continente el campo literario se corresponde directamente con el político por el afán de configurar una tradición nacional en las nuevas patrias emergentes.

En términos genéricos, Casanova considera que el realismo es el género literario más ligado a la cuestión nacional por su relación mimética con lo real al crear la coincidencia ilusoria entre realidad y escritura, lo que permite colmar los intereses políticos de una nación. Es por ello por lo que, en aquellos países bajo tutela política, el realismo suele ser el género hegemónico (2001: 259), como ocurre en la Hispanoamérica decimonónica con las denominadas «ficciones fundacionales» (Sommer, 1993), esto es, aquellas novelas que ficcionalizan la pasión nacional con el fin de reivindicar los intereses de la patria. En este sentido, el subgénero del costumbrismo será especialmente eficaz para este cometido, al retratar las tradiciones populares y arquetipos de una cultura específica.

\section{LA «EXTENSIÓN LINGÜÍSTICA» DEL LENGUAJE LITERARIO}

Ahora bien, conviene detenerse a plantear el modo en que el realismo crea esa ilusión de realidad y, sobre todo, cómo condiciona a la autonomía/dependencia de un texto literario. En otras palabras, qué estrategias retóricas intensifican o atenúan la relación entre texto y contexto (nacional). La hipótesis que defendemos aquí no reside en cuestiones genéricas, como argumenta Casanova, porque nos adscribimos a la tesis de Georg Lukàcs (1966) para quien todos los géneros artísticos constituyen un modo de mediación de la realidad; así, Lukács desmiente el prejuicio de que el realismo sea un reflejo más directo de lo real que otras modalidades narrativas. Si bien es innegable que el nacionalismo decimonónico hace uso del realismo y del costumbrismo para sus fines políticos, el género no sería el factor más determinante sino que sería el lenguaje o, más bien, el registro empleado en todos los niveles de la lengua - sintaxis, léxico, etc.Dicho de otro modo, lo que denominamos aquí la «extensión lingüística» para señalar esa 
distancia/cercanía entre el lenguaje literario y el cotidiano, una diferencia que tradicionalmente se designaba como oralidad y escritura.

Tal binomio ha sido desmentido en las últimas décadas pues el afán de proyectar una supuesta mímesis conversacional - comenzando por Juan de Valdés hasta el siglo XIX - ${ }^{1}$ culminaba en meras convenciones retóricas disfrazadas de una supuesta imitación de lo oral. En «Oralidad y Argentinidad: contornos de un proyecto de investigación» (1997), ${ }^{2}$ Walter Bruno Berg desmitifica los numerosos prejuicios o errores asociados a la definición de oralidad literaria al negar que la misma sea una «realidad lingüística» pues consiste, por el contrario, en un «acto creativo y ficcional» (1997: 24).

Por su parte, Markus Klaus Schäffauer insiste en dicho asunto al afirmar que «la oralidad nunca se halla en estado puro. [...] solo se puede hablar de oralidad en función de algo distinto, que sería lo escrito, que nunca se puede pensar la oralidad sin lo escrito y viceversa» (1997: 231). El crítico define la oralidad como una «construcción literaria de códigos que recién así son percibidos como orales» (1997: 228), y señala que la consideración de los códigos no-literarios en un texto literario se perciben erróneamente como proyección de oralidad. Entonces, si el tradicional binomio oralidad/escritura es falaz, Oesterreicher sugiere descartar la idea de que lo oral se opone a lo escrito y propone, en su lugar, un continuum entre dos polos extremos: la «inmediatez comunicativa» frente a la «distancia comunicativa» (1997: 92-93). En consecuencia, todo discurso se acerca más a uno u otro extremo, siendo difícil - y casi imposible - la existencia de un texto literario que se encuentre en un solo polo.

\section{LA ESCRITORALIDAD EN LA LITERATURA ARGENTINA: EN BUSCA DEL IDIOMA NACIONAL}

Para examinar nuestra hipótesis acerca del grado de asimilación entre la inmediatez comunicativa y el nacionalismo cultural, nos serviremos de las polémicas acerca de la oralidad en la literatura argentina. Berg divide la historia de la «oralidad literaria» del país en cinco grandes momentos; los dos primeros proyectan la total asimilación entre el campo político y cultural durante el siglo XIX y se corresponden con el debate sobre el lenguaje nacional a partir de la in dependencia - Generación del 37-, y a la imitación de la oralidad en el género gauchesco. El tercero se inicia en 1880 cuando la ola inmigratoria genera el miedo a que la lengua se colme de extranjerismos y se busca preservar lo autóctono; el cuarto momento lo protagoniza la vanguardia - los martinfierristas - en un intento por renovar el lenguaje literario desde lo nacional. Finalmente, es alrededor de los años cuarenta cuando el campo literario comienza a escindirse en dos tendencias antitéticas generales. Por un lado, aquellos que buscan la emancipación política de su literatura a través del lenguaje, una tendencia representada sobre todo por Jorge Luis Borges y cuyo programa estaría desplegado en su conferencia «El escritor argentino y la tradición» (1952). Por el otro, hallamos a quienes perseveran en la búsqueda de un lenguaje nacional e intentan imitar el lenguaje cotidiano. En las líneas que siguen, sintetizaremos brevemente los cuatro primeros momentos, según la sugerencia de Berg, para desarrollar con detenimiento la última etapa. Nuestro propósito es dilucidar la evolución de la autonomía/dependencia del campo literario respecto al político en función de la distancia o inmediatez comunicativa de los textos implicados en dicho proceso. Ello se verá desplegado, concretamente, en el ensayo mencionado de

${ }^{1}$ Para un desarrollo más preciso del tema, se a conseja consultar el trabajo de Vian Herrero(1987).

${ }^{2}$ Agradezco a Luis Fernando Rubio el ha berme aportado la bibliografia mencionada. 
Borges, considerado una suerte de manifiesto nacionalista pero antiperonista precisamente por sus reflexiones sobre el lenguaje.

\section{De la Generación del 37 al Centenario}

Tras la independencia, la Generación del 37 tenía como objetivo crear un idioma nacional, como explica Alberdi en Fragmento preliminar al estudio del derecho: «Una lengua es una facultad inherente a la personalidad de cada nación, y no puede haber identidad de lenguas, porque Dios no se plagia en la identidad de las naciones» (1998: 19). Contra la norma española, se consideraba legítima la contaminación foránea siempre y cuando fueran galicismos o anglicismos que, para ellos, eran indicios de modernidad europea y, por tanto, de civilización. ${ }^{3}$ Frente a la Generación del 37, la proyección de la oralidad en la escritura es una de las estrategias fundamentales del género que trasciende posteriormente como literatura nacional: la gauchesca, donde la idea de oralidad connota directamente a la noción de folclore (Rincón, 1997: 153). La gauchesca es, en este sentido, resultado de la convención romántica que considera posible proyectar la oralidad en literatura porque la imitación de ese proceder se vincula a lo popular (y, en consecuencia, a lo nacional). Asimismo, se hace uso de figuras arquetípicas - en este caso, el gaucho - para representar la totalidad del pueblo. Como es sabido, la errónea calificación de «popular» que recibe la gauchesca se debe a que una serie de escritores urbanos intentan copiar el modo de hablar del ambiente rural. Escritores como Bartolomé Hidalgo o Hilario Ascasubi declaran esa búsqueda de inmediatez comunicativa; el segundo advierte que su obra será para algunos «eco de los cantos del gaucho, y [...] para otros, será una violación de las reglas literarias de su lenguaje» (Verdevoye, 1997: 220). Años más tarde, José Hernández transmite la misma idea en la carta-prólogo a Martín Fierro: «concentrando el modo de ser, de sentir, de pensar y de expresarse» (2007: 105). Por su parte, Lucio Mansilla declara: «escribo como hablo» (1904: [s.p.]), un proceder criticado posteriormente por Ricardo Rojas. ${ }^{4}$

La siguiente etapa del recorrido trazado por Berg se caracteriza por una tensión entre aquellos escritores que quieren preservar la lengua nacional ante la «peligrosa amenaza» de lenguas extranjeras, y quienes rechazan despectivamente ese vocabulario criollista creado por la gauchesca. A este segundo grupo lo encabezaría Ernesto Quesada al publicar El problema del idioma nacional (1900) y El criollismo en la literatura argentina (1902) donde plantea la necesidad de alcanzar un lenguaje libre de las «vulgarizaciones criollistas» y de invasiones foráneas, poniendo como modelo la poesía de Rafael Obligado. A la tendencia marcada por Quesada se sumarán los escritores de la generación del Centenario, en concreto, Leopoldo Lugones y Ricardo Rojas. Para el primero, defender la castidad del lenguaje debe ser la acción de todo patriota y, para ello, no es necesario recurrir al habla popular (Funes, 2006: 278). Rojas expone una idea similar en Eurindia (1924): «El pueblo argentino [...] no necesita crearse una lengua nueva para manifestar su genio social, y al hacerlo en castellano pone en su literatura un nuevo contenido» (1951:61).

\footnotetext{
${ }^{3}$ «[El ga licismo ] no se considera un efecto perverso del poliglotismo, sino que se la practica como una manifestación estilística necesaria, incluso estéticamente bella» (Altamirano y Sa rlo, 1981:43).

${ }^{4}$ En Historia de la literatura argentina, escribe: «Este exceso de naturalidad hace deleznable la a rquitectura de Entre Nos y Mis Memorias» (1960:432).
} 


\section{La polémica del meridiano como centro del debate lingüístico}

A principio de los años veinte, tres fenómenos cobran especial protagonismo en lo que atañe a la creación de una lengua nacional: 1) el desarrollo de las letras de tango, en las cuales se pretende proyectar el alma porteña;52) la aparición del teatro gauchesco, en un intento por exportar el género a la ciudad - cuya supuesta oralidad culmina en mera caricatura y parodia (Berg, 1997: 24)—; 3) y la eclosión del martinfierrismo, el movimiento de vanguardia histórica argentino. Las vanguardias hispanoamericanas, a diferencia de las europeas, se caracterizan por una ambivalencia entre el cosmopolitismo propio del pensamiento de vanguardia y la tendencia nacionalista que demanda todo país en proceso de organización. En el caso de Martín Fierro, la revista más representativa de la Argentina, posee una voluntad de ruptura vanguardista al tiempo que reivindica la tradición como revela su título. Consiste en el centro del «campo gravitacional en el mapa de las revistas culturales» de dicha década (Saítta, 2020: [1]), cuyo manifiesto vislumbra el afán por renovar la literatura del país mediante la expresión local. Por ello afirman que «Martín Fierro tiene fe en nuestra fonética» $\left(n^{\circ} 4,1924\right)$.

La búsqueda de un lenguaje nacional en el seno del martinfierrismo se expondrá de manera explícita durante la polémica del meridiano cuando se responda a la propuesta de Guillermo de Torre (en La Gaceta de Madrid, 1927) de establecer el meridiano cultural hispánico en Madrid. ${ }^{6}$ Si durante los primeros números, Martín Fierro había intentado proyectar una imagen anticriollista, ${ }^{7}$ antinacionalista y cosmopolita, ${ }^{8}$ el texto de Torre impulsa en los martinfierristas un sentimiento de unión nacional que exhiben en una serie de respuestas en los números 42,44 y 45 de la revista. La réplica es unánime en su rechazo a la sugerencia de Torre y la identidad lingüística será el pretexto más empleado para justificarlo.

Los argumentos en torno a las diferencias idiomáticas son diversos pero se pueden clasificar en tres tipos: 1) el argentino es un «idioma» distinto al español; ${ }^{9}$ 2) en Argentina se hablan varios idiomas debido al cosmopolitismo generado por la inmigración; ;0 3) toda lengua cambia diacrónicamente y quien no reconozca esa evolución cae en un prejuicio imperialista español. ${ }^{11}$ En suma, la identidad lingüística es la prueba irrefutable de su independencia cultural, lo que se pone en evidencia en el texto satírico firmado con el pseudónimo Ortelli y Gasset, «A un meridiano encontrao en una fiambrera» $\left(n^{\circ} 42,1927\right)$,

${ }^{5}$ El trabajo de Dieter Reichardt(1997) se centra con detenimien to en este punto.

${ }^{6}$ Para un estudio detalla do del tema, consultar Carmen Alemany (1998).

${ }^{7}$ El criollismo, como tendencia del siglo XX que a ctualiza la ga uchesca y la tra splanta al terreno urba no, es condenado por Leopoldo Marechal en «Elga ucho y la nueva literatura rioplatense» $\left(\mathrm{n}^{\circ} 34,1926\right)$.

${ }^{8}$ En el manifiesto se declaran en contra de «la ridícula necesidad de fomentar nuestro nacionalismo intelectual» $\left(\mathrm{n}^{\circ} 4,1924\right)$.

${ }^{9}$ «Hablamos su lengua por casualidad, pero la hablamos tan mal que impertinent emente nos estamos haciendo un idioma argentino. Dentro de unos pocos años nos tendrán que traducir si quieren gozar de nuestro lírico influjo»(Olivari, 1927:6).

${ }^{10}$ «Ya no se puede hablar de identidad lingüística porque todos somos algo políglotas y estamos a costumbrados a escribir en un idioma propio. [...] tenemos en nuestra constitución orgánica el a porte universal»(Ganduglia, 1927:357).

11 «Ustedes no tienen razón en esperar que a cá sigamos hablando en castellano. [...] Y, por otra parte, ¿por qué no se quedaron ustedes hablando latín? ¿Será necesario decir [...] que [el idioma] se transforma fatalmente a pesar de nosotros? [...] el idioma parece ser para España [...] una amplia bandera del imperia lismo» (Rojas Paz, 192 7b: 385). 
donde se intenta imitar la fonética de la oralidad argentina y se emplea un léxico localista con el fin de demostrar las diferencias respecto del español hispánico. ${ }^{12}$

Lo que interesa destacar de los argumentos idiomáticos es que la polémica refuerza la vinculación de Martín Fierro a los intereses nacionalistas. En otras palabras, la polémica disminuye esa autonomía que, en teoría, persigue todo movimiento de vanguardia y que el martinfierrismo en particular parecía anhelar en sus inicios. Y ello ocurre, no únicamente porque se defienda la independencia cultural respecto de España sino, sobre todo, al tomar consciencia de su distinto modo de hablar y proyectándolo mediante la inmediatez comunicativa. Porque la función primordial de esa imitación de la oralidad es que no sea comprendida por extranjeros y, al mismo tiempo, intensificar el sentimiento de unidad entre compatriotas. En definitiva, si la vanguardia significó en Europa una apertura cosmopolita y un afán por la autonomía del arte, en Hispan oamérica derivó en lo opuesto y, durante la polémica del meridiano, fue determinante la extensión lingüística a este respecto.

\section{La distancia comunicativa en Aguafuertes porteñas}

Al margen del ámbito del martinfierrismo, la literatura de Roberto Arlt, entre otros, ${ }^{13}$ es un caso especialmente particular para el tema que nos ocupa como demuestran las primeras críticas negativas hacia su obra: la fama de su «mala escritura» ${ }^{14}$ debido a que en sus textos ha buscado proyectar la oralidad - aunque luego esa proyección se ha matizado y/o desmentido-.${ }^{15}$ En este sentido, la crítica ha contrapuesto a Arlt a la figura de Borges, una oposición que se inicia por parte de los miembros de Contorno al relegar al segundo a favor del primero. Años más tarde, David Viñas insiste en esa dicotomía por la distante relación que uno y otro mantienen con la cultura popular a través del lenguaje. Para el crítico, en sus primeros poemarios Borges se sirve del compadrito para proyectar escenas pintorescas y manifiesta fascinación por lo culto o elevado de esos «bibliotecarios de Alejandría», mientras que Arlt hace uso de lunfardismos pero sin un matiz costumbrista ni un interés de mimetismo conversacional. Esto último se verifica en el significativo gesto de entrecomillar los términos coloquiales que denota, sigue Viñas, un vaivén entre seducción y distancia hacia lo popular (Viñas, 1970: 155-156). En otras palabras, Arlt percibe este vocabulario como algo lejano, distinto, que quiere destacar. Esa diferencia lingüística con Borges fue apuntada también por Ángela Di Tullio (2015), como un factor favorable para el prestigio de Borges fuera de su país frente al localismo

${ }^{12}$ El texto busca proyectar una supuesta oralidad en la escritura. Ofrecemos el inicio del texto como ejemplo de ello: «¡Minga de fratelanza entre la Javie Patria y la Villa Ortúzar! Minga de las que saltan a los zogoibis del batimento tagai que se quedamo estufo, que se... con las tirifila das de su parola senza criollismo»(1927: 7).

${ }^{13}$ Aclaramos que elpanorama litera rio de los veinte y treinta es evidentemente más amplio pero por razones de espacio no podemos detenernos en otros nombres que, con sus contribuciones literarias o ensayísticas, participaron del debate sobre la lengua nacional. Los más importantes son: el líder del martinfierrismo, Macedonio Fernández; los martinfierristas Oliverio Girondo, Nicolás Olivari y Jacobo Fijman; y escritoras como Alfonsina Storni o Silvina Ocampo.

${ }^{14}$ Uno de los primeros críticos que rechazaron la publicación de su obra fue Elías Castelnuovo en la revista Crítica (22/11/1926), donde le recomienda dedicarse a la venta de legumbres antes que a la exploración creativa.

${ }^{15}$ La crítica ha evolucionado a favor de la consideración de la obra de Arlt a partir de su reivindicación por parte de los miembros de Contorno; así David Viñas, como veremos, elogia el estilo a rltiano, queluego repitePiglia en diversas ocasiones. Con respecto a la falacia de la proyección oral de su escritura, remitimos al artículo de María Soledad Blanco, «La ficción de la oralidad en textos narrativos argentinos»». 
de Arlt; es decir, sería la lengua lo que permite que la obra borgiana alcance más autonomía que la de Arlt:

Borges le critica a Arlt su inconsecuencia lingüística no solo en cuanto a su adecuación mimética, sino también por los frecuentes desfases de su prosa, que del «hermoso idioma popular» pasa a un insólito vosotros o a voces arcaizantes [...]. Arlt estandariza a su manera esa lengua en constante cambio y es consciente de eso: casi siempre la opción que elige es [...] desaxiologizar la lengua de valores morales o estéticos ajenos a la verdad de la escritura (Di Tullio, 2015: 239-240).

Destacamos el final de la cita para vincularla a la descripción de Ricardo Piglia sobre el estilo de Arlt, también en contraste al de Borges. En «Sobre Arlt», dice el crítico:

[El de Artl] es un estilo mezclado, diría yo, siempre en ebullición, hecho con restos, con desechos de la lengua. Arlt hablaba el lunfardo con acento extranjero [...]. Hay algo a la vez muy exótico y muy argentino en el lenguaje de Arlt, una relación de distancia y extrañeza con la lengua materna, que es siempre la marca de un buen escritor (Piglia, 2001: 21).

La cita, desde nuestro punto de vista, acierta en diversos aspectos: la pluralidad estilística arltiana (o «conglomerado»), y la lengua nacional concebida, no como la proyección convencional del léxico oral, sino como una hibridez que abarca lo coloquial y el registro alto. En relación a la supuesta oralidad, ya la crítica ha señalado que el lunfardo es el medio para simular el efecto de naturalidad expresiva en la narrativa de Arlt. Aunque generalmente se piensa el lunfardo comovocabulario popular, Óscar Conde lo define como «repertorio léxico integrado por palabras y expresiones de diverso origen, utilizadas en alternancia con las del español estándar y difundido transversalmente en todas las capas sociales y centros urbanos de la Argentina» (2010:228). La cursiva es nuestra para apuntar la desmitificación de Conde hacia el lunfardo, una jerga idealizada por su hipotética diferencia diastrática — de clases bajas y populares - cuando, en realidad, es únicamente diatópica. Por su parte, Balint-Zanchetta indica que Arlt emplea el lunfardo en Aguafuertes porteñas como «interacción entre las funciones metalingüísticas, irónica y expresiva», es decir, para crear la impresión de espontaneidad (2015: 220-221). ${ }^{16}$ No obstante, no debemos ignorar que el propio Arlt fue quien generó el mito del habla popular en torno a su obra para defenderse de los ataques acerca de su mala escritura; así, declara en «La crónica 231» (Aguafuertes porteñas):

Escribo en un «idioma» que no es propiamente el castellano, sino el porteño. Sigo una tradición: Fray Mocho, Félix Lima, Last Reason... Y es acaso por exaltar el habla del pueblo, ágil, pintoresca y variable, que interesa a todas las sensibilidades. Este léxico, que yo llamo idioma, primará en nuestra literatura a pesar de la indignación de los puristas, a quienes no leen [sic] ni leerá nadie (1998: 369).

Por ello, en «El idioma de los argentinos», Arlt se desmarca del lenguaje casticista, como también hará Borges en su ensayo del mismo nombre. Pero, además, no debemos desestimar el influjo que la lectura de traducciones supuso en el estilo de Arlt, como ya apuntara Piglia: «Estilo sobreactuado, de traductor, alude continuamente a ese otro texto

${ }^{16}$ Para Balint-Zanchetta, a demás, el lunfardo no está al mismo nivel que otros registros, por ejemplo, el cocoliche, al cual considera más artificioso porque no se vincula a lo oral sino al subgénero literario del sainete (2015: 221). 
en el que nace y por momentos es su propia parodia: en este sentido habría que decir que cuando Arlt confiesa que escribe mal, lo que hace es decir que escribe desde donde leyó o mejor, desde donde pudo leer» (1973:26).

¿Cómo se proyecta dicha contaminación? Mediante el empleo de términos ajenos al habla oral pero propios del léxico de la traducción, concebida esta como un proceso que busca la supuesta «neutralidad» del lenguaje para estar «al alcance de todos», traspasando las distancias diatópicas —objetivo que, como es sabido, es imposible—. ${ }^{17}$ Arlt logra una pluralidad estilística en su escritura al combinar este vocabulario con palabras tomadas de lo popular, aunque estén entrecomilladas. Tomaremos como ejemplo artículos de Aguafuertes porteñas (1933) que, por su carácter periodístico, está escrito en un estilo intermedio entre lo literario y lo coloquial. El párrafo que sigue, de «La tragedia de un hombre honrado», pone de manifiesto la pluralidad a que aludimos: «Pero más sufre aún cuando, el que se deleita contemplando los encantos de su esposa, es algún mozalbete robusto [...]. Yo comprendo, sin haber hablado una sola palabra con este hombre, el problema que está encarando su alma honrada. Lo comprendo, lo interpreto, lo "manyo"» (1998b: 56).

Arlt emplea el término «mozalbete», ajeno a la jerga oral argentina pero usada con frecuencia en traducciones, junto a «manyar» entre comillas, lunfardismo que significa «comer» o, como en este caso, «observar con atención». El escritor se sirve así simultáneamente de la riqueza que le ofrecen las traducciones y el habla de la oralidad popular en un mismo párrafo. Óscar Conde (2015) ha señalado que el entrecomillar era un proceder común para los lunfardismos entre los escritores de la época, pero Arlt discrimina al entrecomillar algunos lunfardismos frente a otros con un criterio arbitrario que, quizá, responda a la percepción subjetiva que todo hablante posee de su propia lengua. Por ejemplo, en «La vida contemplativa», escribe «labura» sin comillas mientras que sí destaca tipográficamente la palabra «fungi» («perezoso»): «Desde entonces, no labura. Su trabajo se limita a esgunfiarse. Se levanta a las diez de la mañana, se pone el "fungi" y sale hasta la esquina para apoyarse en la vidriera del almacén. De diez a once, se solea. Quieto como un lagarto, se queda arrimado a la pared, con los pies cruzados, los codos apoyados en el alféizar de la vidriera» (1998c: 153). ${ }^{18}$

Arlt aúna dos registros contrapuestos sin solución de continuidad, sin artificios, pues en un mismo párrafo encontramos términos ajenos a la oralidad («alféizan») con lunfardismos. A pesar del vaivén empleado por Arlt —vocabulario propio de la traducción y términos ligados a la oralidad-, en ese continuum entre distancia e inmediatez comunicativa, su estilo se acerca a la primera debido a dos motivos: en primer lugar, porque la traducción es un procedimiento ejemplar de esa distancia por el modo en que se lleva a cabo - neutralización de la lengua meta-. El traductor evita la espontaneidad que supone la inmediatez comunicativa, reflexiona sobre su propia lengua y escoge los términos que percibe más comunes al idioma en cuestión. Si la escritura arltiana se contamina de traducciones, el autor parte de una distancia comunicativa

${ }^{17}$ La neutralización de la traducción está basada en una noción estructuralista de la semántica a partir de la dicotomía denotación/connotación de la palabra; según la semántica estructuralista, el signo lingüístico posee un significado que se mantiene diatópica, diacrónica y diastráticamente, y otro connotativo, heterogéneo, cuyas a lusiones dependen directamente de ca da cultura y período temporal.

${ }^{18}$ Otro ejemplo significativo lo hallamos en «El furbo» (Aguafuertes porteñas): «Elautor de estas crónicas, cuando inició sus estudios de filo logía "lunfarda", fuevíctima de varias a cusaciones entre las que las más graves le sindica ban como un solemne macaneador. Sobre todo en la que se refería alorigen de la palabra berretín, que el infra scripto hacía derivar de la palabra italia na berreto y de la del squenún, que desdoblaba de la squena o sea de la espada en dialecto lombardo»(1981:67). 
inherente a las mismas. En segundo lugar, porque el tratamiento del lunfardismo se lleva a cabo con una distancia crítica que se manifiesta tipográficamente al entrecomillar las palabras, dándole un lugar especial en su escritura, y no un uso familiar. En este sentido, la escritura de Arlt resulta un caso muy particular porque, a pesar de esa supuesta oralidad de sus textos, su estilo se resiste a caer en la asimilación entre lengua y nación. Ese conglomerado de su lenguaje escapa al interés del nacionalismo cultural porque carece del folklorismo, criollismo y tópicos costumbristas, lo cual otorga a su obra mayor grado de autonomía respecto a otros escritores de su generación.

\section{El campo literario de los treinta y cuarenta: Borges ante el nacionalismo}

El campo literario argentino sufre un cambio radical a partir del golpe de Estado del general Uriburu de 1930 pero, sobre todo, debido a que el surgimiento de los nacionalismos en Europa no tardará en resonar entre los nacionalistas del país. El problema de la organización nacional empieza a ser un asunto clave entre la intelectualidad, lo que se hace notar en las revistas culturales. Como es sabido, Sur es el centro del mapa hemerográfico de la época y Victoria Ocampo representa a los intelectuales aristócratas vinculados al liberalismo, contrapuestos a la dictadura de Uriburu. Pero una gran cantidad de revistas que ocuparon un espacio menos preponderante que Sur, emergieron con el fin de apoyar el Golpe y defender el fascismo como cauce adecuado de organización estatal. Algunas son meramente políticas pero muchas de ellas nacen también con intereses culturales - Criterio es una de las más longevas y de mayor trascendencia-. Revistas literarias de índole nacionalista fueron, por ejemplo, la efímera Número (1930-1931) y la posterior Sol y luna (1938-1943) que compartieron colaboradores entre sí. Los escritores de ambas — destacan, por ejemplo, los exmartinfierristas Leopoldo Marechal, Jacobo Fijman o Francisco Luis Bernárdezcultivan una literatura alejada del impulso de vanguardia, pero también de toda temática o estilo criollista. La primera reacción no extraña teniendo en cuenta el retorno al orden que experimenta la poesía de los treinta tras la revolución vanguardista, pero podría resultar contradictorio que poetas vinculados al nacionalismo no saquen provecho de arquetipos criollistas o del vocabulario popular para colmar la tradición nacional de textos patrióticos. La razón reside en el tipo de nacionalismo que ellos propugnan, heredero del nacionalcatolicismo español y fundado en la unidad geopolítica hispánica. En otras palabras, consiste en un nacionalismo contrario a la hegemonía liberal anterior y al antihispanismo de Sarmiento, ya que sus argumentos patrióticos no se basan en su independencia de la Madre Patria; por el contrario, sus fundamentos se alimentan de la identidad hispánica frente a la anglosajona. En consecuencia, el influjo de la literatura española, tan vilipendiado en el pasado, adquiere ahora legitimidad nacionalista - aunque la expresión pueda resultar paradójica- Curiosamente, su nacionalismo se proyecta mediante un estilo y temática hispánicos porque se codifica la asimilación entre nacionalismo e hispanismo. ${ }^{19}$

En este nuevo contexto, Borges ya se había comenzado a desmarcar de la poesía de vanguardia y criollista de los veinte pero precisamente por razones contrarias a las mencionadas. Si bien a finales de la década, Borges se adhirió a las juventudes

\footnotetext{
19 Algunos ejemplos son: los poemas «Fábula de Fileno y Clori» (Sol y luna, 9, 1942), «El emperador vuelve del destierro» (Sol y luna, 2, 1939) y «El a lmirante» (Soly luna, 5, 1941) de Ignacio Anzoá tegui; «Romance del Señor San Ignacio» (Sol y luna, 2, 1939) de Alberto Franco; «Eneas» (Sol y luna, 4, 1940) de José María deEstrada; y poemas que siguen la tradición mística como «El ciervo herido» (Soly luna, 5, 1941) de Leopoldo Marechal.
} 
irygoyenistas, su alejamiento del nacionalismo irá in crescendo a medida que el fascismo se percibe como un peligro para el país. Al observar el rumbo fascista del nacionalismo, Borges busca universalizar sus textos de creación, dejando traslucir un anti-hispanismo evidente que se traduce tanto en su estilo como en su lenguaje. ${ }^{20} \mathrm{Si}$ en sus primeros poemarios buscaba la inmediatez comunicativa con términos que imitaban la oralidad, con el tiempo tomará conciencia de que esa inmediatez no era tal, como revelan su declaración en el prólogo a Luna de enfrente de 1969: «Incurrí [en la primera edición] en la arriesgada adquisición de uno o dos diccionarios de argentinismos, que me suministraron palabras que hoy puedo apenas descifrar: "madrejón”, "espadaña", "estaca pampa"» (2005: 55). ¿Por qué se arrepiente Borges de su léxico anterior? Porque, a partir de los años cuarenta, la inmediatez comunicativa se asimila a "cultura popular»y, por extensión, al movimiento nacionalista que llega al gobierno en 1946, el peronismo. Los intelectuales del régimen de Perón buscarán asentar la cultura nacional a través del criollismo y la tradición gauchesca, así como mediante la reivindicación de lo popular. ${ }^{21}$ Ambos factores apelan tanto a motivos y temas como a la importancia del lenguaje, pues la inmediatez comunicativa es condición necesaria para proyectar el alma nacional. A ello reaccionará Borges en «El escritor argentino y la tradición», una verdadera evidencia del debate que se abre sobre el lenguaje en la literatura nacional y en el influjo del peronismo a partir de 1946, como veremos.

Según Ángel Rama, el peronismo busca dominar la cultura a través de códigos de la clase trabajadora, a la cual otorga un «populismo epidérmico» o «revolucionarismo retórico» con el fin de realzarla o canonizarla como nacional (1976:265). Si antes del peronismo, sigue el crítico, todo elemento popular era absorbido por la cultura dominante, ahora la situación se subvierte porque la subcultura ingresa en ella (1976: 270). Ese proceso se iniciaría de manera aislada con la literatura de Arlt, pero en los cuarenta se torna operación programática cuando la cultura dominada ataca e invierte los códigos convencionales mediante la consideración del pueblo como portador de un

mensaje transformador dentro de la interpretación marxista de la clase proletaria, aun cuando no se distinga nítidamente cuál es su situación concreta y real en ese momento histórico y por lo tanto no se perciba que la subcultura que transporta resulta polisémica, permitiendo que en ella comulgue tanto el romanticismo revolucionario como el «majismo» aristocrático (1976: 277).

¿A qué intelectuales incluye Rama? En general, a los escritores que se contraponen al paradigma borgiano. El crítico escoge una fechaprecisa en que se iniciaría ese proceso: el año 1948, publicación de Adán Buenosayres (1948) de Leopoldo Marechal. En la novela, la mímesis conversacional, la imitación del «acriollamiento» borgiano, el lenguaje escatológico, se entremezclan con un estilo poético y elevado que revela una polifonía de voces diversas. La oralidad, en concreto, funciona como clisé pues

${ }^{20}$ Como explica González Echeverría (2002: 157-158), no es casualidad que Borges quiera reemplazar a Cervantes como escritor del Quijote por un francés en «Pierre Menard, a utor del Quijote» (1940), un cuento que, entre otra s cosas, resulta un manifiesto antihispánico que probablemente fuera impulsa do por el contexto que hemos descrito.

${ }^{21}$ Sobre la figura del ga ucho en la iconografía del peronismo consultar Un Mundo Feliz. Imágenes de los trabajadores en el primer peronismo (2006) de Marcela Gené. Otros estudios que profundizan en la operación cultural nacionalista del régimen son «Los gauchos de Perón. El Círculo Criollo El Rodeo, tra dicionalistas y peronistas (1945-1955)» (2015) y «La Fiesta de la Tradición durante el primer peronismo» (2018) de Matías Casas, y «El criollismo en las luchas por la definición del origen y el color del ethos argentino, 1954-1955» de Ezequiel Adamovsky. 
pone al descubierto ciertos estereotipos culturales que son objeto de burla y parodia (Zubieta, 1997: 115). Pero ese estilo sincrético sería causa, en parte, de los primeros rechazos que recibiera la novela a partir de su publicación - conviene pensar en la similitud con esa «mala escritura» que se le atribuía a Arlt—. Según sus primeros detractores, Marechal no emplea con naturalidad esa mezcla de registros. Así, por ejemplo, González Lanuza describe su escritura como un «abundoso estilo de los novelistas españoles del siglo pasado» ${ }^{22}$ (1997: 878). Pero, como es sabido, es Julio Cortázar el primer defensor de Adán Buenosayres (Realidad, 1949), porque la considera uno de los avances más memorables de la novela argentina: «lo que Marechal ha logrado en los pasajes citados es la aportación idiomática más importante que conozcan nuestras letras». Porque, afirma Cortázar, los argentinos «estamos haciendo un idioma [...] para nuestra expresión necesaria. Un idioma que no necesita del lunfardo (que lo usa, mejor), que puede articularse perfectamente con la mejor prosa literaria y fusionar cada vez mejor con ella — pero para irla liquidando secretamente y en buena hora — (1997: 881) (la cursiva es nuestra).

El comentario de Cortázar es relevante no solo por ser el primer escritor argentino que valora favorablemente la renovación estilística de Marechal sino además porque señala ese proceso idiomático indicado luego por Rama: la búsqueda de un idioma propio que se desentienda progresivamente de la «prosa literaria» o del lenguaje de la cultura dominante. Tal es la novedad de la escritura de Adán Buenosayres que le costaría, junto con otros aspectos, su marginación en el campo literario dominante de los cuarenta - fundamentalmente por parte del grupo Contorno — .23 Pero lo que nos interesa destacar es la estrecha vinculación de la novela con el nacionalismo y el peronismo a pesar de no cumplir con el requisito de Casanova sobre la relación entre el realismo y la autonomía de las obras literarias, ya que Adán Buenosayres adelanta la experimentación vanguardista de los años sesenta, desmarcándose del realismo. De ahí que sugerimos que es la inmediatez comunicativa la que, en ocasiones, determina la autonomía de textos/autores en el campo literario de su país. Cabe aclarar que nuestra hipótesis no descarta la de Casanova sino que se basa en el debate lingüístico de la intelectualidad argentina que, como hispanoamericanos, buscan desligarse de España; por tanto, no sería arriesgado aventurar que la teoría de Casanova se sostiene en países centrales del polisistema o de la República Mundial de las Letras mientras que ese esquema se revierte en los periféricos durante el siglo XX. Así, si Joyce con su experimentación vanguardista renueva el panorama literario irlandés y se contrapone al nacionalismo, ${ }^{24}$ Marechal produce una novela tan experimental como Ulises pero con el fin contrario: establecer una cultura nacional según los intereses del gobierno de entonces, el peronismo. ${ }^{25}$ Con

${ }^{22}$ Por su parte, Rodríguez Monegal (1997) señala que Marechal se limita a copiar el lenguaje coprológico de James Joyce, una imitación que resulta a rtificiosa para el crítico.

${ }^{23}$ Como es sabido, el rechazo de Marechal durante los cuarenta y cincuenta estuvo más relacionado con cuestiones biográficas de su a utor que con el propio texto (su adhesión al peronismo y su condición católica).

${ }^{24}$ «Cua ndo se a dvierten los primeros efectos de la rebelión, es decir, de la diferenciación literara y los primeros recursos litera rios se pueden reivindicar y a propiar [...] un nuevo espacio literario nacional. En ese esta dio surgen los escritores de la "segunda generación" como James Joyce: valiéndose de los recursos litera rios nacionales ya constituidos como tales, van a alejarse del modelo nacional y na ciona lista de la literatura e inventar las condiciones de su autonomía, esto es, de su liberta d»(Casanova, 2001:417418).

${ }^{25}$ Hemos hecho tal a claración para resaltar la diferencia entre Adán Buenosayres y el Ulises puesto que Marechal fue a cusado de plagiar a Joyce por sus primeros detractores: González Lanuza, Rodríguez Monegaly Jitrik. 
este ejemplo, podemos ver con mayor claridad una de las diferencias entre centro y periferia en su distinta relación con el nacionalismo.

Retomando nuestra hipótesis, sabido es que la lectura de Adán Buenosayres impacta en Cortázar, como demuestran las similitudes que comparte con Rayuela, ${ }^{26}$ pero el interés por renovar el lenguaje literario se observa en textos de Cortázar anteriores, como apunta Rama respecto al cuento «Ómnibus» (1951) donde

la autonomía narrativa que surge de la instalación en la inmediatez, se rubrica y ensancha por los recursos lingüísticos empleados: hay un trabajo de simplicidad que procura abrir el foco de percepción para que en él quepa ese lector eventual procedente de otro estrato cultural, sin que por ello resulte eludido el lector culto, a quien se le reservan segundas posibilidades interpretativas, más ricas (1976: 289).

La cursiva es nuestra para destacar la relación entre dos conceptos clave para el tema que nos ocupa: la autonomía narrativa y la inmediatez lingüística. Rama sostiene que la inmediatez comunicativa de la escritura de Cortázar implica un acercamiento entre la cultura dominante y la popular. Esa particularidad novedosa conlleva, a su vez, una mayor autonomía narrativa pues, para Rama, significa que el texto no se debe ni a una ni a otra cultura, adquiriendo así una independencia gracias a la inmediatez de su escritura. En otras palabras, el crítico sostiene la tesis contraria que proponemos nosotros y, en cierta manera, se opone a esa voluntad que Cortázar esgrimía en la reseña a Adán Buenosayres, esto es, un afán de crear un idioma que manifieste su origen argentino. A este debate aludido por Rama responde Borges en «El escritor argentino y la tradición». La conocida conferencia es una reacción al ataque lanzado contra su primera poesía por parte de Héctor Murena desde Sur (164-165, 1948). Según Sebastián Hernáiz, el ensayo de Borges consiste en una diatriba contra los nacionalistas argentinos, es decir, el peronismo ya hegemónico en 1952. Eso significa que Borges no está respondiendo a Murena, más bien, está acatando su embestida:

Murena escribe contra la obra de Borges de los años veinte, contra esa poesía de «impostación nacionalista», plena del color local que la mirada turística exigiría. Y [...] llamativamente Borges convoca en su texto la posición de Murena pero no para polemizar con ella y defenderse sino que, por el contrario, retoma sus argumentos y los utiliza para desligarse también él mismo de su primera obra. La pregunta que se impone, entonces, es por qué, cuando Murena lo ataca, Borges acata (Hernáiz, 2013: 88-89).

La respuesta es evidente: Borges no necesita defenderse porque él concuerda con las ideas de Murena y ataca, más bien, a escritores nacionalistas en boga durante el contexto de enunciación en que escribe, es decir, el peronismo. Explica Hernáiz que la intelectualidad peronista, en su objetivo de reivindicar unatradición nacional, no recupera únicamente la poesía gauchesca, sino que también se sirve de la poesía de los veinte y, en concreto, la revista de vanguardia Martín Fierro en que Borges participó. Tal es el verdadero impulso que promueve la necesidad de escribir «El escritor argentino y la tradición» — aunque el texto de Murena fuera el motor primero-

No es de extrañar, entonces, que Borges procurara «desligarse» $[. .$.$] de su obra temprana$ $[\ldots]$. Pero esto no sucede directa ni únicamente por las vinculaciones $[\ldots]$ que se pudieran

\footnotetext{
${ }^{26}$ Para un desarrollo más detenido, se a conseja consultar Ja vier de Na vascués (1997).
} 
entablar entre esa temprana obra y el nazismo [...] sino por el modo en que el nacionalismo cultural, hegemónico en el peronismo [...] comienza a leer la obra del primer Borges como su tradición: Borges reniega de su primera obra mientras que el peronismo se apropia de esa obra temprana de Borges y la pone a funcionar como antecedente en el plano estético de los cambios político-culturales impulsados entre 1945 y 1955 (Hernáiz, 2019: 90).

En su ensayo, entonces, Borges no reivindica la autonomía de su obra con respecto a la nación, sino que quiere desacreditar el prejuicio de que la inmediatez comunicativa otorga al texto una impronta más nacional que la distancia comunicativa porque, en definitiva, la primera no es menos artificiosa que la segunda. Así, afirma que el léxico de la poesía gauchesca — aprovechada por el peronismo como poesía nacional — no es oralidad sino «incorrecciones [que] son obra de la ignorancia» (2012:153). Y ejemplifica su hipótesis con el libro nacional por excelencia, Martín Fierro, donde Hernández emula (o intenta emular) el habla de los gauchos; pero, según Borges, sus mejores versos son precisamente aquellos donde se eleva el lenguaje poétic o, es decir, en la payada: «Cuando esos dos gauchos, Fierro y Moreno, se ponen a cantar, olvidan toda afectación gauchesca y abordan temas filosóficos [...]. Su propósito es hacer de la poesía algo alto» (2012: 154). Borges reivindica la payada con el argumento contrario a los nacionalistas porque para él la distancia comunicativa enriquece el texto y, aún más importante, no le arrebata su carácter argentino. De ahí su reflexión final: «nuestro patrimonio es el universo; ensayar todos los temas, y no podemos concretarnos a lo argentino para ser argentinos: porque o ser argentino es una fatalidad, y en ese caso lo seremos de cualquier modo, o ser argentino es una mera afectación, una máscara» (2012: 162).

En otras palabras, el mensaje de Borges no es, de ningún modo, antinacionalista, -no es secundario, a este respecto, que se dirija a un interlocutor argentino cuando afirma «nuestro patrimonio es el universo»-. Pero más importante es su conclusión de que todas las obras argentinas que menciona a lo largo del ensayo son plenamente nacionales a pesar de no cumplir con los tópicos que, según los nacionalistas, deberían alcanzar para «ser argentinas». De este modo, «El escritor argentino y la tradición» adquiere así el carácter de manifiesto nacionalista pero antiperonista porque Borges no se quiere desmarcar de la literatura nacional sino de la operación cultural llevada a cabo por el peronismo al asimilar lo popular, los temas localistas y la inmediatez comunicativa, a lo argentino. Su afán no es, entonces, universalizar su propia literatura ni reivindicar la autonomía de sus textos sino desarticular esa convención romántica promulgada por el peronismo y, a su vez, reivindicar la argentinidad de su obra, a pesar de la distancia comunicativa de su estilo. En definitiva, en dicho ensayo, Borges no busca solo formar parte de la República mundial de las Letras que hemos descrito en nuestra introducción, sino, sobre todo, posicionarse en el centro de su campo literario nacional.

\section{CONCLUSIONES}

Tras exponer nuestra propuesta acerca de la relación entre inmediatez comunicativa y autonomía/dependencia de las obras literarias respecto del nacionalismo cultural, hemos querido ejemplificarlo en el ámbito hispanoamericano, en concreto, en el campo literario argentino. Se ha descrito, de manera muy sintética, un recorrido diacrónico de los principales debates en torno a la inmediatez lingüística entre los intelectuales, desde el siglo XIX al XX, con el fin de explicar su trasformación durante 
los cuarenta. La operación del régimen peronista rescata la asimilación entre nación, tradición gauchesca, criollismo y cultura popular que, en el terreno literario, se traduce tanto en motivos o temas literarios como en el fetichismo por imitar el habla oral, incluso en escritores no nacionalistas como Cortázar. A este proceso reacciona Borges quien, en «El escritor argentino y la tradición», reivindica implícitamente la centralidad de su obra en el campo literario nacional, contraponiéndose a la asimilación entre inmediatez comunicativa y nacionalismo. Para él, la distancia comunicativa puede funcionar para la escritura de una obra plenamente argentina — en su caso_-, desafiando así la legitimidad nacionalista adquirida por el peronismo. Proponemos pues que el ensayo borgiano es un manifiesto contra esa inmediatez comunicativa en la escritura literaria así como una reclamación nacionalista de la argentinidad de sus textos.

\section{OBRAS CITADAS}

Adamovsky, Ezequiel (2015), «El criollismo en las luchas por la definición del origen y el color del ethos argentino, 1954-1955», EIAL, 26, 1, pp. 31-63.

Alberdi, Juan Bautista (1998), Fragmento preliminar al estudio del derecho, Buenos Aires, Ciudad Argentina.

Alemany Bay, Carmen (1998), La polémica del meridiano intelectual de Hispanoamérica 1927: estudio y textos, Alicante, Universidad de Alicante.

Alemany Bay, Carmen (2012), «Nacionalismo y vanguardia a propósito de la polémica "Madrid, meridiano intelectual de Hispanoamérica"», en Carmen de Mora Valcárcel y Alfonso García Morales (eds.), Viajeros, diplomáticos y exiliados. Escritores hispanoamericanos en España (1914-1939), Madrid, Peter Lang, pp. 319-332.

Altamirano, Carlos y Beatriz Sarlo (1981), Ensayos argentinos: de Sarmiento a la vanguardia, Buenos Aires, Centro Editor De América Latina.

Anónimo (1924), «Manifiesto de Martín Fierro», Martín Fierro, 4, pp. 1-12.

Arlt, Roberto (1981), Obras completas, Buenos Aires, Omeba.

Arlt, Roberto (1998), Obras completas 2, Buenos Aires, Losada.

Balint-Zanchetta (2015), «Las funciones del lunfardo en Aguafuertes porteñas de Roberto Arlb», en Rolf Kailuweit, Volker Jaeckel y Ángela Di Tullio (eds.), Roberto Arlt y el lenguaje literario argentino, Madrid, Iberoamericana, pp. 213-230.

Berg, Walter Bruno (1997), «Oralidad y Argentinidad: contornos de un proyecto de investigación», en Oralidad y argentinidad: estudios sobre la función del lenguaje hablado en la literatura argentina, Tübigen, Gunter Narr Verlag, pp. 19-27.

Blanco, María Soledad (2015), «La ficción de la oralidad en textos narrativos argentinos», Cuadernos de la Facultad de Humanidades y Ciencias Sociales, $<$ http://www.redalyc.org/html/185/18547708004/>.

Borges, Jorge Luis (1987), «El escritor argentino y la tradición», en Discusión, Buenos Aires, Emecé, pp. 151-162.

Borges, Jorge Luis (2005), «Prólogo» a Luna de enfrente, en Obras completas I, Barcelona, Emecé, p. 55.

Casanova, Pascale (2001), La República mundial de las Letras, Barcelona, Anagrama.

Casas, Matías (2015), «Los gauchos de Perón. El Círculo Criollo El Rodeo, tradicionalistas y peronistas (1945-1955)», Prácticas de oficio, 15, pp. 1-12.

Casas, Matías (2018), «La Fiesta de la Tradición durante el primer peronismo: de José Hernández a Juan Domingo Perón», Sudamérica: Revista de Ciencias Sociales, 8, pp. 119-144.

Cortázar, Julio (1997), «Leopoldo Marechal: Adán Buenosayres», en Jorge Lafforgue y Fernando Colla (coords.), Adán Buenosayres, Madrid, Galaxia Gutemberg, pp. 882-886. 
Conde, Óscar (2010), «El lunfardo en la literatura argentina», Gramma, 21, 47, pp. 224-246.

Conde, Óscar (2015), «Roberto Arlt y el lunfardo», en Rolf Kailuweit, Volker Jaeckel y Ángela Di Tullio (eds.), Roberto Arlt y el lenguaje literario argentino, Madrid, Iberoamericana, pp. 199-211.

Di Tullio, Ángela (2009), «Meridianos, polémicas e instituciones: la cuestión del idioma», en Noé Jitrik (ed.), Historia crítica de la literatura argentina. VII Rupturas, Buenos Aires, Emecé, pp. 569-596.

Di Tullio, Ángela (2015), «Las excursiones lingüísticas de Roberto Arlt», en Rolf Kailuweit, Volker Jaeckel y Ángela Di Tullio (eds.), Roberto Arlt y el lenguaje literario argentino, Madrid, Iberoamericana, pp. 231-240.

Even-Zohar, Itamar (1990), «Polysystem Theory», Poetics Today, 11, 1, pp. 9-26.

Gené, Marcela (2006), Un Mundo Feliz. Imágenes de los trabajadores en el primer peronismo 1946-1955, Buenos Aires, Fondo de Cultura Económica.

González Echeverría, Roberto (2002), Crítica práctica/práctica crítica, México, Fondo de Cultura Económica.

González Lanuza, Eduardo (1997), «Leopoldo Marechal: Adán Buenosayres», en Jorge Lafforgue y Fernando Colla (coords.), Adán Buenosayres, Madrid, Galaxia Gutemberg, pp. 876878.

Hernández, José (2007), Martín Fierro, Madrid, Cátedra.

Jitrik, Noé (1997), «Adán Buenosayres: la novela de Leopoldo Marechal», en Jorge Lafforgue y Fernando Colla (coords.), Adán Buenosayres, Madrid, Galaxia Gutemberg, pp.883-896.

Lukács, Georg (1966), Problemas del realismo, México DF., Fondo de Cultura Económica.

Mansilla, Lucio V. (1904), Mis memorias. Buenos Aires, Hachette, $<$ http://www.cervantesvirtual.com/obra-visor/mis-memorias-infanciaadolescencia/html/ff3a45a2-82b1-11df-acc7-002185ce6064_8.html>

Navascués, Javier (1997), «Sobre novela argentina: Rayuela y Ad̄́n Buenosayres», en Jorge Lafforgue y Fernando Colla (coords.), Adán Buenosayres, Madrid, Galaxia Gutemberg, pp. 957-966.

Oesterreicher, Wulf (1997), «Pragmática del discurso oral», en Oralidad y argentinidad: estudios sobre la función del lenguaje hablado en la literatura argentina, Tübigen, Gunter Narr Verlag, pp. 86-100.

Olivari, Nicolás (1927), «Madrid, meridiano intelectual Hispano América», Martín Fierro, 42, p. 6.

Piglia, Ricardo (1973), «Roberto Arlt: una crítica de la economía literaria», Los Libros, 29, pp. 22-27.

Piglia, Ricardo (2001), «Sobre Roberto Arlt», en Crítica y ficción, Barcelona, Anagrama, pp. 2128.

Quesada, Ernesto (1983), «El criollismo en la literatura argentina», en Alfredo V. E. Rubione (ed.), En torno al criollismo, Buenos Aires, Centro Editor de América Latina, pp. 103230.

Rama, Ángel (1976), «Rodolfo Walsh: el conflicto de culturas en Argentina», Escrituras: teoría y criticas literarias, 2 , pp. 279-301.

Reichardt, Dietrich (1997), «Oralidad y las letras de tango», en Walter Bruno Berg, Markus Klaus Schäffauer (eds.), Oralidad y argentinidad: estudios sobre la función del lenguaje hablado en la literatura argentina, Tübigen, Gunter Narr Verlag, pp. 163-169.

Rincón (1997), «La oralidad, ¿un problema específico de la literatura latinoamericana?», en Walter Bruno Berg, Markus Klaus Schäffauer (eds.), Oralidady argentinidad: estudios sobre la función del lenguaje hablado en la literatura argentina, Tübigen, Gunter Narr Verlag, pp. 140-162.

Rodríguez Monegal, Emir (1997), «Adán Buenosayres: una novela infernal», en Jorge Lafforgue y Fernando Colla (coords.), Adán Buenosayres, Madrid, Galaxia Gutemberg, pp. 923927.

Rojas, Ricardo (1951), Eurindia, Buenos Aires, Losada. 
Rojas, Ricardo (1960), Historia de la literatura argentina II, Buenos Aires, Kraft.

Rojas Paz, Pablo (1927), «Imperialismo baldío», Martín Fierro, 42, p. 6.

Saítta, Sylvia. (2020), «El periódico Martín Fierro como campo gravitacional», Orbis Tertius, 24 30, e129.

Schäffauer, Markus Klaus (1997a), «Glosando los debates (a modo de epílogo)», en Walter Bruno Berg, Markus Klaus Schäffauer (eds.), Oralidady argentinidad: estudios sobre la función del lenguaje hablado en la literatura argentina, Tübigen, Gunter Narr Verlag, pp. 228237.

Schäffauer, Markus Klaus (1997b), «Modelos narrativos de escritOralidad en la literatura argentina. 1900-1925: continuidad y ruptura», en Walter Bruno Berg, Markus Klaus Schäffauer (eds.), Oralidad y argentinidad: estudios sobre la función del lenguaje hablado en la literatura argentina, Tübigen, Gunter Narr Verlag, pp. 98-113.

Sommer, Doris (1993), Ficciones fundacionales. Las novelas nacionales de América Latina, México DF., Fondo de Cultura Económica.

Verdevoye, Paul (1997), «Oralidad e identidad en la literatura argentina - algunos aspectos históricos», en Walter Bruno Berg, Markus Klaus Schäffauer (eds.), Oralidad y argentinidad: estudios sobre la función del lenguaje hablado en la literatura argentina, Tübigen, Gunter Narr Verlag, pp. 218-227.

Vian Herrero, Ana (1987), «La mimesis conversacional en el Diálogo de la lengua de Juan de Valdés», Criticón, 40, pp. 45-79.

Viñas, David (1970), «Después de Cortázar: historia e interiorización», en Actual narrativa latinoamericana, La Habana, Centro de Investigaciones Literarias Casa de las Américas, pp. 147-187.

Zubieta, Ana María (1997), «Lugares comunes de la cultura nacional», en Walter Bruno Berg y Markus Klaus Schäffauer (eds.), Oralidad y argentinidad: estudios sobre la función del lenguaje hablado en la literatura argentina, Tübigen, Gunter Narr Verlag, pp. 114-121. 